\title{
Pagamento por Serviços Ambientais (PSA) e Agroecologia: uma abordagem crítica à agricultura moderna
}

\section{Payments for Environmental Services (PES) AND Agro-ECOLOGY: UNE CRITIQUE APPROACH A MODERN AGRICULTURE}

\author{
* Natália Jodas \\ ** Rogério Silva Portanova
}

* Mestranda do Programa de Pós-Graduação em Direito da Universidade Federal de Santa Catarina (UFSC) da área de concentração Direito, Estado e Sociedade; linha de pesquisa Direito, Meio Ambiente e Ecologia Política. E-mail: najodas@ gmail.com

** Professor Associado da Universidade Federal de Santa Catarina; Doutorado em Sociologie et Anthropologie Du Politique pela Université Paris 8 Vincennes-Saint-Danes (1994) e Pós-Doutorado pela Universidade Lusíada de Lisboa (2012). e-mail: rogerio.portanova@ufsc.br
Resumo: Aeconomia agrícola do Brasil emoldurou uma realidade intrinsecamente dependente dos insumos externos produzidos pela indústria química e biotecnológica. No contexto do agronegócio e do protótipo das monoculturas, esta pesquisa analisa, por um vértice crítico, o modo como o Estado brasileiro incentiva irrefletidamente práticas rurais atreladas à utilização de substâncias químicas sob o pretexto da "modernização". Traçados os efeitos nocivos dos venenos agrários à saúde humana e à qualidade do meio ambiente, discutem-se as políticas públicas e atos normativos adotados pelo governo nessa matéria, discutindo-se se tais medidas são, de fato, condizentes à perspectiva precaucional consolidada na Constituição Federal e legislação ambiental esparsa. Em contrapartida, com vistas a sublinhar alternativas mais aliadas à salvaguarda ecológica, discorre-se sobre o papel do Pagamento por Serviços Ambientais (PSA) como mecanismo estatal de fomento ao emprego de métodos agroecológicos e familiares de produção no campo, respaldando-se a necessária abordagem sistêmica do instituto para a consecução da racionalidade ambiental. A metodologia de pesquisa empregada é a revisão bibliográfica da literatura jurídica, sociológica e ecológica tocante à temática, bem como a análise documental legislativa e de organismos públicos.

Palavras-chave: "Agricultura Moderna" brasileira; Agrotóxicos; Pagamento por Serviços Ambientais (PSA); Agroecologia.

Abstract: Brazil's rural economy has been intrinsically dependent of imported supplies, from the chemical and biotech industries. In the context of corporate farming and monoculture, this research analyzes, critically, how the Brazilian government subsidizes rural practices intensely related to the use of chemical substances, under the modernization pretext. After the perverse effects of the chemicals have been underlined, this article discusses the policies adopted by government in these matters, 
and if these policies are, indeed, protecting the environment, in light of the precaution principle, as inscribed in the Brazilian Constitution. In another light, the role of Payment for Environmental Services (PES) is also studied, mainly as a mechanism of development of agro-ecological practices in farming. The article maintains that a systemic approach to PES is necessary for attaining environmental rationality. The methodology used in this study is the bibliographic review of Law, sociology and ecology literature, and review of public documents.

Keywords: Brazilian "Modern Agriculture"; Pesticides; Payments for Environmental Services (PES); Agro-ecology. 


\section{INTRODUÇÃO}

Com o objetivo de induzir um olhar crítico sobre o atual formato de produção agrícola no Brasil, a presente pesquisa discorre sobre os aspectos nocivos causados ao meio ambiente e à saúde humana pela expansão da monocultura e dos agrotóxicos, principais elementos da "agricultura moderna". Nesse contexto, são desmitificadas as noções de "científico" e "tecnológico", terminologias difundidas pelo pensamento ocidental para deslegitimar os conhecimentos e saberes das populações tradicionais ligadas a terra.

Sequencialmente, levantam-se dados sobre a economia e o consumo de químicos no setor agrário do país, discriminando-se os efeitos adversos do uso de venenos para o solo, água, animais, ecossistemas e seres humanos. Refletese, em seguida, sobre o papel da política estatal na manutenção de um protótipo agrário dependente de insumos externos advindos das indústrias químicas e biotecnológicas. Salienta-se, também, que a maior parte dos créditos e isenções fiscais governamentais é destinada aos grandes proprietários rurais relacionados ao agronegócio.

Ressaltada a necessidade de o Estado brasileiro delimitar uma estratégia econômica aliada às diretrizes da racionalidade ecológica, pondera-se sobre a função dos instrumentos jurídico-econômicos como política pública de incentivo à preservação do meio ambiente e da qualidade de vida humana. Nesse contexto, insere-se o Pagamento por Serviços Ambientais (PSA) de fomento às práticas agroecológicas como possível ferramenta estatal de inversão ao modelo globalizado de agricultura.

O trabalho utiliza como metodologia a revisão da literatura jurídica, sociológica e ecológica tangente à temática de pesquisa, bem como a consulta a documentos institucionais produzidos por órgãos públicos e por organizações privadas.

\section{CONTORNOS DA AGRICULTURA "MODERNA": AS MONOCULTURAS E OS AGROTÓXICOS}

A produção agrícola nos últimos sessenta anos transformou-se abruptamente nas mais distintas regiões do globo. O cultivo dos pequenos produtores rurais e das comunidades familiares, apegado aos modos de vida tradicionais ligados a terra e às práticas naturais, foi substituído aceleradamente por vastas plantações monocultoras. 
A disseminação das monoculturas de espécies de "crescimento rápido" na silvicultura e das "variedades de alto rendimento" na agricultura (SHIVA, 2002, p. 92) caracterizou a revolução agrícola do século XX, mais conhecida como "Revolução Verde". Embasada na necessidade de aumentar a produtividade de alimentos, dita revolução culminou na explosão da biotecnologia, na produção de fertilizantes e herbicidas sintéticos, no alto grau de especialização, na terceirização de funções e na concentração de renda (FAGUNDEZ, SILVEIRA, ALVES, SILVEIRA, 2012, p. 72).

A modernização da agricultura não trouxe mudanças apenas nas técnicas de geração e manejo agrários, mas impôs, também, subjetivamente, a ideia de "desenvolvimento", em franca oposição à "estagnação" e "atraso", associados à lavoura tradicional. Os saberes e costumes locais de outrora foram taxados como "primitivos" e "não científicos", sem qualquer possibilidade de resistirem diante do novo e "necessário" sistema de produção em alta escala, trazido pelo "pacote" tecnológico.

Nesse raciocínio, Vandana Shiva (2003, p. 23) explica que:

Quando o saber local aparece de fato no campo da visão globalizadora, fazem com que desapareça negando-lhe o status de um saber sistemático e atribuindo-lhe os adjetivos de "primitivo" e "anticientífico". Analogamente, o sistema ocidental é considerado o único "científico" e universal. Entretanto, os prefixos "científico" para os sistemas modernos e "anticientífico" para os sistemas tradicionais de saber têm pouca relação com o saber e muita com o poder.

A sociedade ocidental infundiu sua organização político-econômica como um protótipo universal, no qual o processo de expansão agrícola, imperado pela uniformidade, monocultura, utilização de substâncias químicas e patenteamento de tipologias de vida, tornou-se sinônimo de crescimento e prosperidade. Instituiuse uma nova relação entre natureza e homem, caracterizada pela troca da diversidade dos sistemas produtivos pelos modelos construídos em laboratório, enrijecendo-se um método fortemente dependente de insumos externos, de elevada densidade técnica e científica e alto investimento de capital (ALVES, 2008, p.64).

O regime de rotação de culturas e do uso múltiplo da biodiversidade transformou-se em uma "compacta fábrica", comandada pelas sementes especializadas das monoculturas (soja, trigo, laranja, cana-de-açúcar) e 
dependentes diretamente do uso de inseticidas. O cultivo de um único produto vai de encontro com os "princípios pelos quais a natureza opera: trata-se de agricultura como um engenheiro a concebe" (CARSON, 2010, p. 26).

O desequilíbrio ecológico impera neste círculo vicioso, já que o uso intensivo de venenos origina maior vulnerabilidade das plantas às pragas e doenças que, por sua vez, serão remediados com mais biocidas, contribuindo a uma desestabilização permanente no metabolismo das espécies vegetais. A indústria química produtora e incentivadora dos produtos químicos agrícolas é a mesma que oferece os "medicamentos" para a cura dos desequilíbrios causados:

O negócio dos pesticidas transformou-se num dos melhores negócios, e um dos mais fáceis. Tão fácil quanto o negócio dos entorpecentes. Quanto mais se vendia, mais crescia a demanda. A situação atual se assemelha a uma conspiração muito bem bolada. Os mesmos grandes complexos industriais que induziram o agricultor a que desequilibrasse ou destruísse a microvida do solo com sais solúveis concentrados que são os adubos minerais sintéticos, oferecem então os "remédios" para curar os sintomas dos desequilíbrios causados. (LUTZENBERGER, 2012, p. 53 e 54).

No Brasil, assim como nos países periféricos, a abertura à agricultura biotecnológica, em meados de 1960, acabou por originar graves distorções. As políticas de desenvolvimento agrícola foram direcionadas à modernização das grandes propriedades, "aprofundando ainda mais as desigualdades e exclusão social no meio rural, principalmente em se tratando dos agricultores familiares" (MULLER, LOVATO, MUSSOI, 2003, p. 103).

O êxodo rural acelerou-se (décadas de 70 e 80), em razão da distribuição desigual de benefícios, da deterioração das condições socioeconômicas dos agricultores, da marginalização e degradação ambiental (ALVES, 2008, p. 65). Noutro aspecto, a mecanização e tecnificação fizeram com que os centros de decisão e poder, ligados aos processos agrícolas, ficassem afastados dos locais de aplicação, originando complexas e longas redes verticais de poder (ALVES, 2008, p. 64).

A perda da autonomia do lavrador familiar junto com os seus saberes sobre o gerenciamento da vida na propriedade foi sentida nas distintas realidades brasileiras, sendo que hoje quando o agricultor não está afastado das atividades do campo, é um mero acessório dentro do ciclo produtivo capitaneado pelas corporações químicas. Diversidade tornou-se antônimo de produtividade (SHIVA, 2003, p.163). 
As escolas de agronomia do país também foram dominadas pelos ideais da indústria química, cuja visão simplista difundiu que as pragas e enfermidades das plantas são inimigas arbitrárias e implacáveis, cabendo ao produtor rural seu extermínio (LUTZENBERGER, 2012, p. 55).

$\mathrm{O}$ formato de agricultura propagado pela Revolução Verde (monoculturas + sementes industriais + venenos) levou o Brasil a ser um dos principais fornecedores de produtos agropecuários do mundo. De acordo com o Ministério da Agricultura, Pecuária e Abastecimento (2010), o país é o que mais produz e exporta açúcar, café, suco de laranja, carne bovina, tabaco, cana-de-açúcar e etanol.

Paralelamente, no ano de 2008, o Estado brasileiro tornou-se o maior mercado consumidor de agrotóxicos do globo (IBAMA, 2010). O total de produtos químicos consumidos nas unidades de federação é proporcionalmente maior nos locais onde a atividade agrícola é mais expressiva, como nos estados do Rio Grande do Sul, São Paulo e Mato Grosso (IBAMA, 2010).

A problemática relativa à expansão da "fórmula" do agronegócio brasileiro está exatamente nas consequências advindas das suas máximas: deslegitimação dos saberes locais e, em contrapartida, "beatificação" do conhecimento supostamente científico; desconstrução das redes de experiência e decisões locais do campo; destruição da biodiversidade e diversidade de produção em virtude das monoculturas; desequilíbrio do sistema ecológico pela intervenção da engenharia genética e indústria química.

Sumariados os principais aspectos tocantes à moldura "desenvolvimentista" da sociedade hodierna e, caracterizada a economia agrária no âmbito do Brasil, discorrem-se, no próximo item, os principais efeitos sociais e ecológicos acarretados pelo uso de venenos na agricultura.

\subsection{Os riscos socioambientais dos agrotóxicos}

Diferentemente do pensamento comum, a agroquímica floresceu a partir da disputa bélica das duas guerras mundiais, entre o período de 1914 a 1945, quando os químicos das forças armadas americana e alemã desenvolveram substâncias com o intuito de, durante os conflitos, devastarem as colheitas e florestas dos países inimigos (LETZENBERGUER, 2012, p. 51). Após as lutas armadas, a indústria química precisou migrar para outros mercados, momento no qual a agricultura apareceu como demanda ideal (LUTZENBERGUER, 2012, p. 52). 
O termo "agrotóxico" acopla diversas substâncias químicas, em geral sintéticas, como inseticidas, fungicidas, herbicidas, formicidas, dentre outros (NODARI, 2012, p. 113 e 114). A utilização destes materiais na agricultura tem o objetivo de aumentar a produtividade agrícola por meio do controle de insetos, doenças e enfermidades presentes nas plantas.

É muito comum o emprego de nomes diversos aos agrotóxicos, como "defensivos agrícolas" ou "produtos para defesa agrícola", expressões, em geral, adotadas pela indústria química ou pelos sindicatos ligados às empresas produtoras destes insumos. De fato, o que se almeja com essas outras terminologias é omitir ou diminuir a ideia sobre os efeitos adversos causados pelo seu uso.

Nessa linha, sublinha-se que o grande diferencial em relação às consequências nocivas destes produtos está na sua composição. Isso porque, antes do período das grandes guerras, as ferramentas empregadas para o combate às pragas e anomalias vegetais eram derivadas de minerais e plantas, encontrados na própria natureza, enquanto que, no pós-guerra, passou-se a elaborar engenhosas manipulações de moléculas em laboratórios que envolviam a substituição de átomos ou a alteração de sua disposição (CARSON, 2012, p.30).

A intervenção cada vez maior das substâncias orgânicas nos processos ecológicos, isto é, de compostos que tinham o carbono como elemento básico, propiciou a difusão de matérias com alta capacidade de bioacumulação na natureza. Isso se deve ao fato do carbono ser formado por átomos com habilidade quase infinita de se unirem uns aos outros em diversas configurações (CARSON, 2012, p. 32).

Como consequência, diferentes tipologias de poluentes orgânicos passaram a se acumular no metabolismo vegetal, animal, humano ou mesmo a serem transportados por longas distâncias nas águas, vento e solo. O uso desmesurado e imprudente dos venenos fez com que os microssistemas ecológicos sentissem intensamente os efeitos químicos.

A começar que quando aplicados em campos de produção, parte significativa dos agrotóxicos é absorvida pelas plantas e tão logo se torna resíduo nos alimentos, enquanto que a outra porção pode ir para os cursos d' água ou lençóis freáticos (NODARI, 2012, p. 131). Os solos, conjugados por uma infinidade de formas de vida e essenciais na propagação da humosfera ("manta viva"), são extremamente vulneráveis aos inseticidas, em vista das perturbações biológicas provocadas por estes (LAGO, 1991, p. 119). 
A ideia sobre a complexidade de teias de vida existentes nos solos está distante dos olhos humanos. Difícil ainda é supor que a aplicação de biocidas para matar determinadas larvas subterrâneas de insetos, destruidores de plantações, não seja também capaz de eliminar outras formas de invertebrados fundamentais à decomposição da matéria orgânica (CARSON, 2012, p. 60).

Rachel Carson aponta que o mais importante ao lembrarmos-nos dos venenos no solo é a "sua longa persistência, medida não em meses, mas em anos" (2012, p. 61). Além disso, é preciso investigar em que extensão estes venenos são absorvidos e penetram no tecido das plantas, o que vai depender diretamente da característica da superfície, do cultivo, da natureza ou mesmo da concentração do químico (2012, p. 62). Contudo, escassas são as pesquisas tocantes às consequências sofridas pelo solo quanto às intensas pulverizações.

A poluição direta das águas (rios, lagos, bicas, riachos) é sentida tão logo nas primeiras aplicações químicas junto às lavouras, já que o vento é um instrumento difusor desses compostos. Estudos elaborados no Brasil e em outros países têm revelado a incidência de agrotóxicos nos sistemas hídricos superficiais e subterrâneos usados para consumo humano direto (NODARI, 2012, p. 134).

A contaminação dos cursos d' água pelo uso de venenos intensifica-se à medida que o modelo de agricultura moderna é unido ao uso desses produtos orgânicos. Assim, vastas áreas de florestas vêm a chão para viabilizar os cultivos monocultores, erradicando-se as principais fontes de proteção natural dos leitos aquáticos, como as matas ciliares e florestas nativas. Nessas paisagens restam o assoreamento dos rios, a erosão nos solos e a diminuição da potabilidade das águas.

Igualmente grave é saber que há registros de resíduos tóxicos em amostras de água coletadas em sistema de abastecimento público urbano. Embora os municípios estejam obrigados a fazer pesquisas sobre a água oferecida aos cidadãos, estes resultados dificilmente chegam ao conhecimento da população (NODARI, 2012, p. 135).

Pesquisas que objetivaram analisar as consequências da utilização do glifosato, principal elemento do Roundup (herbicida sistêmico), indicaram sua nocividade a minhocas, insetos e ratos (NODARI, 2012, p. 125). Conjuntamente, se afeta a cadeia alimentar do ciclo de vida de muitas aves predadoras de insetos, desestabilizando todo ecossistema (CARSON, 2012, p. 104).

Despontam estudos sobre os efeitos colaterais causados pelos agrotóxicos à saúde humana. A exposição aos pesticidas aumenta proporcionalmente em 
relação aos riscos de doenças quanto maior for o contato direto com eles. Por exemplo, a chance de câncer é maior nas crianças que vivem no campo do que naquelas que vivem nos centros urbanos (NODARI, 2012, p. 119).

Oportuno enfatizar que os produtos sintéticos elaborados na atual conjuntura da agricultura "moderna" têm um poder imenso de penetrar nos processos mais vitais do corpo e "alterá-los de forma sinistra e, muitas vezes, mortal” (CARSON, 2012, p. 30). Estes "elixires da morte”, tal como designado pela bióloga Rachel Carson, destroem as enzimas cuja função seja proteger o corpo contra danos, bloqueiam os processos de oxidação que fornecem energia ao organismo e podem desencadear, em certas células, a lenta mudança que conduz a doenças malignas $(2012$, p. 30).

Colhe-se do Sistema Nacional de Informações Toxicológicas que, no ano de 2011, foram registrados no Brasil o total de 98.765 mil casos de intoxicação humana por produtos químicos. Somente no centro de informações de Porto Alegre, anotaram-se 20.137 mil envenenamentos em indivíduos (SINITOX; 2011). Anomalias crônicas atreladas a sintomas neurológicos de déficit motor, sensitivo e cognitivo foram encontrados nestas fontes (LUFCHITZ; BAROTTO; ZANNIN; 2012, p. 198).

De acordo com o Programa de Análise de Resíduos de Agrotóxicos em Alimentos (PARA), elaborado pela ANVISA - Agência Nacional de Vigilância Sanitária, das amostras realizadas para diagnosticar a presença de resíduos nos alimentos nas unidades federativas do Brasil, detectou-se que $29 \%$ foram insatisfatórias, isto é, apresentaram resíduos de agrotóxicos não autorizados pela legislação. Das análises satisfatórias (leia-se: dentro da legalidade), apurouse a presença de resíduos tóxicos em 36\% delas. Significa dizer que em apenas $35 \%$ dos alimentos investigados não foram encontrados venenos (ANVISA, 2013, p. 28).

O quadro de riscos socioambientais motivados pelas pulverizações na agricultura denota o quanto a sociedade brasileira está vulnerável em relação à qualidade de vida presente e futura. Nesse caminho, tímidas são as ações do Poder Público no sentido de inibir o aumento progressivo do uso de agrotóxicos na produção agrícola.

De modo impressionante, o contrário tem sido a realidade: o Estado brasileiro incentivou e permanece fomentando um modelo agrário devastador da natureza e transbordante no emprego de químicos. Soma-se a esse fato a carência geral de informações sobre o leque de danos proporcionado pelos pesticidas na vida humana. 
Nesse trajeto, expõe-se, no item subsequente, o percurso do governo nacional no que se refere ao estímulo financeiro, fiscal e normativo à consolidação de uma agricultura não sustentável.

\section{NA CONTRAMÃO: INCENTIVOS GOVERNAMENTAIS À PRÁTICA DAAGRICULTURAQUÍMICA}

Uma série de políticas executadas por diferentes governos exerceu a função de instituir a modernização agrícola. Um marco central neste processo foi a criação, em 1965, do Sistema Nacional de Crédito Rural, o qual condicionava a obtenção de crédito agrícola à obrigatoriedade de compra de produtos químicos (FERREIRA, 2013, p.39).

Estabelecido pela Lei $\mathrm{n}^{\circ}$. 4.829/1965, o programa de crédito rural inaugurou o período denominado "milagre brasileiro", configurado nos anos seguintes ao golpe militar (1964). Foi no final da década de 1960 que a política econômica brasileira, guiada pelos militares, sustentou-se pela modernização das estruturais sociais e econômicas e pela internacionalização da economia.

O crédito rural oficial, principal instrumento propulsor do novo protótipo agrário, foi altamente seletivo, pois sua oferta restringiu-se aos médios e grandes produtores rurais (HESPANHOL, 2008, p. 82). Enquanto isso, pequenos proprietários, arrendatários, parceiros e meeiros não tiveram acesso em razão de não disporem das garantias patrimoniais exigidas pelo sistema financeiro, fato que resultou, como comentado alhures, no êxodo rural, marginalização do campo, enfraquecimento da agricultura familiar e enchimento desordenado dos centros urbanos.

É certo que a construção agrícola desse período voltou-se ao consumo de capital e tecnologia externa: grupos especializados forneciam insumos, máquinas, sementes, adubos, agrotóxicos e fertilizantes, sendo que a opção de aquisição era facilitada pelo acesso ao crédito rural (BALSAN, 2006, p. 126). O slogan do desenvolvimento econômico a qualquer custo engrenou o país, assim como outras economias emergentes, a flexibilizarem as normas ambientais, de fiscalização e responsabilização judicial (FAGUNDEZ; SILVEIRA; ALVES; SILVEIRA, 2012, p. 77).

Nesse contexto, o Brasil, desde 1997, renova continuamente o Convênio ICMS nº. 100/1997, em que se estabelece a redução de $60 \%$ da base de cálculo do ICMS - Importo sobre Circulação de Mercadorias e Prestação de 
Serviços - para agrotóxicos (inseticidas, fungicidas, formicidas, herbicidas, dentre outros). Referido convênio foi prorrogado até 31 de julho de 2014 (BRASIL, 1997), dando mostras que as recorrentes postergações serão permanentes.

O governo federal também isenta completamente os agrotóxicos da cobrança do IPI - Imposto sobre Produtos Industrializados -, do PIS/PASEP Programa de Integração Social e Programa de Formação do Patrimônio do Servidor Público - e Confins - Contribuição para o Financiamento da Seguridade Social - por meio, respectivamente, dos Decretos $n^{\circ} .7 .660 / 2011$ e $n^{\circ} .5 .630 /$ 2005 (FERREIRA, 2013, p. 108).

No que se refere à legislação ambiental, a Lei 7.802/1989 dispõe sobre pesquisa, experimentação, produção, importação, exportação, destino final de resíduos e embalagens, registro, controle, entre outros, dos agrotóxicos, seus componentes e afins. $\mathrm{O}$ controle sobre o registro e circulação destes produtos é realizado pelo Ministério da Saúde, Ministério do Meio Ambiente e Ministério da Agricultura, Pecuária e Abastecimento (artigo 2 ${ }^{\circ}$, caput, Decreto $n^{\circ}$. 4.074/ 2002).

Nesse particular, enaltece-se que não existe um prazo de validade para o registro dos agrotóxicos, posto que sua reavaliação ocorre somente quando se "apresentarem indícios de redução de sua eficiência agronômica, alteração dos riscos à saúde humana ou ao meio ambiente" (artigo 13, Decreto $n^{\circ} .4 .074 /$ 2002). Isso quer dizer que, contrariando os princípios da precaução e prevenção, o dispositivo determina que somente após a consumação de danos à qualidade humana e ambiental é que será analisada a viabilidade ou não do registro desses químicos.

Convém mencionar que o artigo $3^{\circ}, \S 6^{\circ}$ da Lei $n^{\circ} .7 .802 / 1989$ não estabeleceu entre suas alíneas a vedação de registro de agrotóxicos proibidos em seu país de origem. É perceptível uma política complacente à facilitação do uso de substâncias tóxicas, concretizada na elaboração de normas fiscais e ambientais brandas em relação à sua entrada, comercialização e uso.

Em outra vertente, a agricultura familiar, insistente nos modos tradicionais agronômicos, recebe tímidos e ineficientes estímulos por parte do Estado. Embora o plantio familiar tenha acesso a financiamento a baixas taxas de juros por meio do PRONAF - Programa Nacional de Fortalecimento da Agricultura Familiar - há um contínuo enfrentamento de dificuldades para a manutenção do modo de produção tradicional, pois apenas o acesso ao crédito oficial não é suficiente para viabilizá-lo (HESPANHOL, 2008, p. 86). 
Muito comuns são os programas governamentais de incentivo à agricultura familiar, como o PRONAF, levarem os agricultores à especialização produtiva, situação em que o produtor é levado a plantar o que a política pública financia. Neste caso, sobressai a plantação de grãos e commodities agrícolas, como milho, soja, trigo, fumo, em plena contradição à lógica de vida das unidades familiares (CONTERATO; GAZOLLA; SCHENEIDER; 2007, p.38).

A mobilização por um modelo agrário sustentável, embasado na reconfiguração das identidades locais, na preservação da biodiversidade e na desestimulação à excessiva prática química, deve ser a meta de um Estado obediente aos princípios do Direito Ambiental, tal como cristalizados na Constituição da República. A racionalidade econômica deve passar por um longo processo de construção e institucionalização dos princípios em que se fundamenta a vida sustentável no planeta (LEFF, 2010, p. 32).

Diante de um quadro econômico completamente atrelado ao fundamentalismo do mercado e arraigado à crença no progresso sem limites (LEFF, 2010, p. 33), urge discutirem-se novos mecanismos governamentais capazes de embasar uma nova racionalidade ambiental. Nesse aspecto, discorrese, na sequência, sobre a possibilidade de determinados instrumentos econômicojurídicos serem implementados a favor de um projeto agrícola vinculado aos preceitos ecológicos.

\section{PAGAMENTO POR SERVIÇOS AMBIENTAIS (PSA): POR UMA AGRICULTURA MAIS SUSTENTÁVEL}

\subsection{Instrumentos econômicos na preservação ambiental}

O texto constitucional brasileiro fixou o Estado como regulador da atividade econômica, capaz de dirigi-la e ajustá-la aos valores e princípios constitucionais (PERALTA, 2014, p. 16). Os artigos 170 e 174 da Constituição Federal estabeleceram a intervenção do Estado no domínio econômico com o escopo de respaldar suas funções de fiscalização, incentivo e planejamento junto às ações privadas com vistas a sopesar a justiça social e a defesa do meio ambiente, entre outros preceitos fundamentais.

Dessa forma, a entidade governamental passou a interceder nas operações econômicas por meio das medidas diretas e indiretas. A primeira condiz aos sistemas de comando e controle, cuja configuração dá-se na imposição de standards, limites e proibições sobre atividades consideradas 
lesivas ao meio ambiente; enquanto que a segunda refere-se a mecanismos de caráter promocional, que atuam no incentivo de condutas benéficas à natureza (PERALTA, 2014, p. 17).

De certo modo, pode-se dizer que a utilização de apenas uma destas tipologias de ingerência estatal não parece ser suficiente a promover a tutela efetiva do bem ambiental. No que diz respeito às ferramentas de controle, por exemplo, é sabido que a falta de estrutura e desamparo dos órgãos ambientais de fiscalização permitiram a ineficácia de importantes arcabouços legais, tais como o Código Florestal (antiga Lei $\mathrm{n}^{\circ}$.4.771/1965), a lei de crimes ambientais (Lei $\left.n^{\circ} .9 .605 / 1998\right)$, entre outros. A consequência acaba sendo o recorrente apelo aos Tribunais que, muitas vezes, não resguarda a devida proteção ao meio ambiente.

Por outro lado, o emprego único e desmedido de instrumentos econômicos pode gerar suscetibilidade à lógica individualista e mecanicista da racionalidade mercadológica. Nesse quesito, necessário que o Estado e os entes federativos, condutores das políticas de incentivo à preservação ambiental, estejam alinhados à ordem da economia ecológica. Como ensinado por LEFF (2010, p. 37/38):

A economia ecológica parte de um conjunto de pressupostos e de princípios epistemológicos críticos. [...] A economia ecológica vem gerando, assim, conceitos criadores de novas tensões com a economia convencional - balanço energético do processo econômico, bens posicionais, distribuição ecológica, incomensurabilidade de processos -, abrindo-se para o campo adjascente da economia política, onde se manifestam os conflitos socioambientais resultantes do impacto da economia sobre a natureza. Esses conflitos deveriam ser resolvidos através de um diálogo político, a partir dos conhecimentos trazidos pela ciência e dos interesses dos grupos afetados da população, por intermédio de uma racionalidade comunicativa, dos direitos legitimados, dos processos jurídicos estabelecidos e eventualmente da pressão de movimentos sociais, para além da impossível valorização econômica (grifa-se).

Importa clarear que diversos são os instrumentos econômicos de indução à conservação ambiental e inúmeras são as formas de sua implementação. Por isso, enfatiza-se a importância das escolhas políticas estarem conectadas aos anseios da justiça social e, consequentemente, direcionarem-se para a consecução de meios de gestão ambiental ligados à desconstrução da racionalidade econômica do presente. 
Nesse aspecto, o Pagamento por Serviços Ambientais (PSA), espécie de instrumento econômico-jurídico, será detalhado nas próximas linhas no contexto dos programas de fomento à agroecologia.

\subsection{PSA e o incentivo a práticas agroecológicas}

Em razão das atividades econômicas (agrícolas, industriais, consumistas) gerarem externalidades negativas ao meio ambiente (poluição da água, ar, contaminação do solo, lençóis freáticos, extinção da biodiversidade), a Economia passou a discutir formas dos empreendedores internalizarem os custos socioambientais provocados pelo uso dos recursos naturais. Desse pressuposto, a valoração econômica ambiental tornou-se fundamental para a gestão dos recursos ecológicos, bem como para a tomada de decisões com grande impacto ambiental, uma vez que se "permitiu inserir de forma mais realista o meio ambiente nas estratégias de desenvolvimento econômico" (ORTIZ, 2003, p.82).

De acordo com Daily (1997), os serviços ecossistêmicos abrangem as condições e os processos pelos quais os ecossistemas sustentam a vida humana. Estes serviços são classificados em serviços de provisão (capacidade de o ecossistema prover bens, como alimentos, fibras, recursos genéticos, água); serviços reguladores (benefícios obtidos a partir dos processos naturais que sustentam a vida, como a regulação do clima, ciclos da água, desintoxicação); serviços culturais (relacionados à importância dos ecossistemas fornecerem benefícios recreativos, espirituais, estéticos); serviços de suporte (processos naturais necessários para que outros serviços possam existir, como ciclagem de nutrientes, formação dos solos, polinização e dispersão de sementes) (SEEHUSEN; PREM; 2011, p. 18).

Diante dessas considerações teóricas e de um cenário nacional marcado por uma agricultura vinculada à devastação florestal para expansão das fronteiras monocultoras (dependentes do uso de agrotóxicos), verifica-se, em decorrência, o aumento da erosão, do assoreamento hídrico e da poluição do solo, lençóis freáticos, águas e plantas, nos ambientes rurais e urbanos. Em contrapartida, vêm sendo implementados projetos de Pagamento por Serviços Ambientais (PSA) com vistas a garantir que os dispositivos normativos de proibição de dano ambiental tenham maior concretude social.

O PSA está fundamentado no reconhecimento de que os ecossistemas provêm uma grande variedade de serviços ambientais que beneficiam a sociedade em sua integridade, todavia, estes serviços geralmente não são 
preservados devido à falta de incentivos financeiros para conservá-los (DEPARTAMENTO DE DESARROLO SOSTENIBLE DE LA ORGANIZACIÓN DE LOS ESTADOS AMERICANOS, 2005). A proposta do instrumento tem o objetivo de conscientizar os beneficiários dos serviços ambientais sobre sua importância e valorizar quem contribui diretamente para a sua preservação (ALTMANN, 2009, p. 85).

A prestação de serviços ecossistêmicos envolve um grau de incerteza em relação à efetiva provisão do serviço e seu volume (NUSDEO, 2012, p. 17). Na expectativa de assegurar mais aceleradamente a qualidade da água, ar e dos biomas, os programas de PSA estabelecidos, muitas vezes por iniciativa governamental, visam à recuperação das matas ciliares, biodiversidade, captura de carbono e paisagem.

Uma das facetas do PSA seria associar-se ao incentivo às boas práticas agrícolas, ao uso sustentável da terra, à formação de sistemas agroflorestais e ao desenvolvimento e articulação de medidas participativas comunitárias. A agroecologia, cujo escopo está atrelado à realização de análises críticas sobre a agricultura produtivista e à orientação voltada ao manejo sustentável dos agroecossistemas (HESPANHOL, 2008b, p. 128), é um instrumento opositor à política agrária hegemônica em vigor.

Ora, na perspectiva de um Estado que se declara consoante aos princípios constitucionais ambientais (artigo 225, $\$ 1^{\circ}$, incisos I e V da CF), mostra-se razoável a consolidação de uma nova estratégia econômica hábil a engendrar novos rumos ao desenvolvimento agrícola presente. A agroecologia pressupõe:

a construção de uma nova ciência comprometida com os interesses sociais e ecológicos dos movimentos populares e com a articulação entre as ciências sociais e naturais na compreensão dos problemas socioambientais da atualidade, buscando cada vez mais soluções realmente sustentáveis. Pressupõe, ainda, um enfrentamento político com os interesses econômicos que dominaram o desenvolvimento do capitalismo industrial na agricultura durante os últimos 130 anos (MOREIRA; CARMO; 2004, p. 55). (grifa-se)

Focado a redesenhar os traços do protótipo agrícola nacional, o PSA poderia ser uma espécie de política pública voltada a investir na difusão dos preceitos agroecológicos no âmbito da agricultura familiar, a reconstruir a soberania do agricultor, a segurança alimentar e o resgate dos modos de vida e saberes locais do campo. Isso porque, como instrumento de fomento, os projetos de PSA podem exigir de contrapartida a adoção de práticas agrícolas 
sustentáveis pelos proprietários envolvidos no programa (provedores de serviços ecológicos).

A concepção de PSA como ferramenta de preservação ambiental, especialmente de matas ciliares e biodiversidade, precisa contemplar uma percepção sistêmica, indispensável à construção da racionalidade ecológica. Exatamente nesse particular, a edificação de uma abordagem complexa do PSA enseja a promoção da agroecologia unida a relevantes aspectos, como o incentivo à fertilidade natural dos solos (emprego de métodos conservativos de esterco, adubação verde e restos de colheitas), ao controle natural das pragas (inimigos naturais e outras técnicas), preservação da biodiversidade, ausência do emprego de técnicas que envolvam organismos geneticamente modificados, fortalecimento das redes sociais do campo, valorização dos conhecimentos locais e autonomia do agricultor familiar.

A produção ecológica, antes de uma opção econômica, é uma alternativa de vida e trabalho, contrapondo-se ao desmatamento e exaustão dos recursos naturais (GRÍGOLO, 2008, p. 244). Por isso, as políticas públicas de PSA devem abarcar questionamentos aos impactos ecológicos, à devastadora concentração de riquezas e à exploração das forças de trabalho dos pequenos proprietários rurais.

No Brasil, 28\% das áreas são ocupadas por sistemas agroflorestais (IBGE, 2006), sendo que a agricultura orgânica ocupa apenas $0,34 \%$ sobre o total de área agricultável, índices ainda tímidos se comparados ao total de área disponível no país (SAQUET, 2008, p. 144). Movimentos sociais para cultivos alternativos ou mesmo orgânicos têm sido desenvolvidos por conta própria, posto que são raros os subsídios governamentais ou a ajuda financeira direta a estes fins (SAQUET, 2008, p. 138).

Em agosto de 2012, o governo federal publicou o Decreto $n^{\circ} .7 .794$, instituidor da Política Nacional de Agroecologia e Produção Orgânica (PNAPO) e, no ano de 2013, lançou edital (edital nº. 81/2013) para seleção de propostas de apoio financeiro a projetos integradores de atividades de pesquisa, educação e extensão para a construção e socialização do conhecimento de práticas voltadas à Agroecologia e aos Sistemas Orgânicos de Produção (CNPq, 2013).

O resultado da chamada está previsto para março de 2014, sendo que o apoio financeiro alcança $\mathrm{R} \$ 14$ milhões de reais (CNPq, 2013). Há de verificarse, ainda, se o formato de execução dos projetos será coerente com a concepção da Agroecologia, abarcando, entre os seus instrumentos, iniciativas de PSA 
com a finalidade de assistir, de forma plena e efetiva, os agricultores rurais interessados nas práticas sustentáveis.

\subsection{Experiências de agroecologia e a necessidade de maior ingerência positiva estatal}

\subsubsection{Região de Torres - Santa Catarina e Rio Grande Do Sul}

A área denominada "Região de Torres" localiza-se na divisa entre o litoral norte do Rio Grande do Sul e o extremo sul de Santa Catarina. Os municípios componentes são: Dom Pedro de Alcântara (RS), Itati (RS), Mampituba (RS), Morrinhos do Sul (RS), Torres (RS), Terra de Areia (RS), Três Cachoeiras (RS), Três Forquilhas (RS) e Praia Grande (SC). O bioma Mata Atlântica perfaz a geografia local, cuja qualificação é de "área de Extrema Importância Biológica”, segundo o Ministério do Meio Ambiente (GONÇALVES, 2011, p. 26).

De acordo com André L. Gonçalves (2011, p. 25), há predomínio de minifúndios, com tamanho médio de 10 hectares por unidade de produção, nos quais a mão de obra é predominantemente familiar. A região foi marcada pelo intenso cultivo da banana com uso de tecnologias modernas (adubação química e agrotóxicos).

Os problemas ambientais derivados das plantações de arroz, fumo e banana, tais como a contaminação do solo, água e diminuição dos remanescentes de Mata Atlântica, fizeram com que, a partir do apoio de organizações civis, os agricultores criassem uma associação com o objetivo de vender produtos orgânicos com maior oportunidade de comércio.

A partir das orientações advindas do Centro Ecológico (ONG) sobre a constituição de sistemas agroflorestais, as monoculturas de banana e fumo foram convertidas em sistemas de produção e manejo integrados por diversas espécies, como cedro, embaúba, sobragi, louros, canela, dentre outros (GONÇALVES, 2011, p. 27). Além disso, os sistemas agroflorestais inseriram variados usos das espécies cultivadas, combinando produção de alimentos com geração de renda e preservação ambiental (GONÇALVES, 2011, p. 27).

Entretanto, diversas barreiras são apontadas em relação ao desenvolvimento das práticas agroflorestais e agroecológicas na região em comento. Nesse ínterim, a ausência de políticas públicas à produção ecológica, 
a desvalorização do trabalho pela sociedade (MARTINS, 2012, p. 56), bem como a falta de espaço para o comércio, a insuficiência da assistência técnica e dos programas de capacitação (GONÇALVES, 2011, p. 29) podem ser indicados como gargalos do programa.

Como se observa, mobilizações da sociedade civil organizada têm transformado realidades marcadas pela expansão monocultora (banana, fumo, arroz) e pela utilização química. Porém, o aparato estatal junto a estas propostas ecológicas é imprescindível à continuidade e fortalecimento das práticas agroecológicas.

\subsubsection{Zona da Mata de Minas Gerais}

A parte originária da Zona da Mata mineira era praticamente coberta pela vegetação da Mata Atlântica, região onde a agricultura cafeeira levou à elevada devastação florestal e à erosão dos seus solos (MEIER, 2011, p. 48). O Centro de Tecnologias Alternativas da Zona da Mata (CTA-ZM) em união com as organizações da agricultura familiar e o movimento agroecológico impulsionaram ações de sistemas agroflorestais acoplando 25 comunidades de 11 municípios (MEIER, 2011, p. 48).

Estudos de campo realizados na região (MEIER, 2011, p. 51) expõem dificuldades na efetivação dos ideais agroecológicos e agroflorestais em virtude da ausência de políticas que estimulem e deem condições econômicas e técnicas para que estes sistemas consigam aumentar o número de adesões. Segundo André Meier, os programas de PSA estaduais existentes (Bolsa Verde Minas Gerais e Bolsa Floresta Amazonas), embora estejam avançando na preservação das florestas, tem sido demasiadamente tímidos em relação à abordagem agroflorestal.

Para o citado pesquisador, "o desenvolvimento agroflorestal na região é fortemente associado às iniciativas das populações tradicionais que ocupam este território. Pouco se pode associar às experiências com sistemas agroflorestais motivados por intervenções de políticas ou governança" (2011, p. 52).

Percebe-se, assim, a imprescindibilidade do Estado enveredar estratégias político-agrárias de mote ecológico, subsidiando e preenchendo os obstáculos oriundos do seu próprio modelo agrícola insustentável. 


\section{CONSIDERAÇÕES FINAIS}

O Estado brasileiro, seguindo a tendência dos países periféricos, tem sustentado todo o modelo de agricultura "moderna" difundido pela Revolução Verde. A entrada de insumos agrícolas externos (maquinários, agrotóxicos, sementes, adubos sintéticos) foi impulsionada no período da ditadura militar, tendo os governos subsequentes prosseguido com a lógica econômica do agronegócio.

Na última década, o país tornou-se o primeiro exportador de commodities de açúcar, café, suco de laranja, carne bovina, tabaco, cana e etanol, e, paralelamente, o maior consumidor de agrotóxicos do globo. Ano após ano, o Sistema Nacional de Informações Tecnológicas (SINITOX) registra marcas crescentes de intoxicação humana pelo uso de produtos químicos, ao passo que apenas 35\% dos nossos alimentos não são diagnosticados com venenos, segundo o Programa de Análise de Resíduos Agrotóxicos em Alimentos (2011/2012).

Por outro lado, os incentivos governamentais às práticas agroecológicas e florestais têm sido escassas e, quando existem, restringem-se a oferecer créditos rurais condicionados à execução da mesma agricultura monocultora e química, a exemplo do PRONAF. Enquanto isso, isenções fiscais são continuamente concedidas para a entrada e circulação das sementes e compostos sintéticos fabricados pelas multinacionais.

Como anotado, instrumentos de incentivo econômico do Estado são fundamentais para operarem em pareceria com os de comando e controle. Nessa senda, relevante que as políticas públicas estejam preocupadas com os ideais da economia ecológica, cujos pressupostos estão arraigados à valorização dos custos socioambientais nas atividades econômicas.

$\mathrm{Na}$ perspectiva de aliar a racionalidade ambiental com as estratégias estatais, o Pagamento por Serviços Ambientais (PSA) foi a proposta da pesquisa, no sentido de que o instituto possa exigir como contrapartida a implantação dos princípios da Agroecologia, modelo de produção agrícola oposto à política agrária vigente. Indispensável que o PSA contemple uma abordagem sistêmica, capaz de unir o formato produtivo sem químicos com a retomada das forças do agricultor familiar, seus saberes locais e poder de articulação no campo.

Os projetos agroecológicos em vigor no sul (Região de Torres) e sudeste (Zona da Mata Mineira) do país demonstram que as iniciativas derivadas da sociedade civil necessitam de subsídios do Estado para que encontrem maiores espaços no mercado e na cadeia produtiva. Por isso, o PSA, no âmbito destes 
programas, viria a fomentar a continuidade dos projetos e contribuir para o reconhecimento social dos benefícios trazidos pela Agroecologia.

\section{REFERÊNCIAS}

ALVES, Adilson Francelino. Conhecimentos convencionais e sustentáveis: uma visão de redes interconectadas. In: ALVES, Adilson Francelino; CARRIJO, Beatriz Rodrigues; CANDIOTTO, Luciano Zanetti Pessôa (org.). Desenvolvimento territorial e agroecologia. São Paulo: Expressão Popular, 2008.

AGÊNCIA NACIONAL DE VIGILÂNCIA SANITÁRIA. Programa de Análise de Resíduos de Agrotóxicos em Alimentos (PARA). Relatório de Atividades 2011/2012. Disponível em: <www.anvisa.gov.br〉. Acesso em: 10/out./2013.

ALTMANN, Alexandre. O desenvolvimento sustentável e os serviços ambientais. In: RECH, Adir Ubaldo; ALTAMANN, Alexandre. Pagamento por Serviços Ambientais. Imperativos jurídicos e ecológicos para a preservação e a restauração das matas ciliares. Caxias do Sul: EDUCS, 2009.

BALSAN, Rosane. Impactos decorrentes da modernização da agricultura brasileira. Campo-Território: revista de geografia agrária, v. 1, n. 2, p. 123151, ago. 2006.

CARSON, Rachel. Primavera Silenciosa. São Paulo: Gaia, 2010.

CONSELHO NACIONAL DE DESENVOLVIMENTO CIENTÍFICO E TECNOLÓGICO [CNPq]. Chamada Pública MCTI/SETEC/CNPq n. ${ }^{\circ}$ 92/ 2013. Disponível em: file: $</ / / C$ :/Users/User/Downloads/ Chamada\%20NIT\%20-\%2092_\%202013.pdf $>$. Acesso em 15 de janeiro de 2014.

CONTERATO, Marcelo Antônio; GAZOLLA, Marcio; SCHNEIDER, Sergio. A dinâmica agrícola do desenvolvimento da agricultura familiar no Alto do Uruguai, Rio Grande do Sul: suas metamorfoses e reações locais. In: 
TONNEAU, Jean Philippe; SABOURIN, Eric (org.). Agricultura Familiar. Interação entre Políticas Públicas e Dinâmicas Locais. Porto Alegre: Editora UFRGS, 2007.

DAILY, G.C. Nature Services: Societal dependence on natural ecossystems. Washington, D.C. Island Press, 1997.

DEPARTAMENTO DE DESARROLO SOSTENIBLE DE LA ORGANIZACIÓN DE LOS ESTADOS AMERICANOS. Pagos por servicios ambientales. San Jose, 2005. Disponível em: < http:// www.oas.org/dsd/Documents/Lospagosporserviciosambientales.pdf $>$. Acesso em: 15 de dezembro de 2013.

FAGUNDEZ, Paulo Roney Ávila; SILVEIRA, Clóvis Eduardo Malinverni da; ALVES, Elizete Lanzoni; SILVEIRA, Karine Grassi Malinverni. Considerações éticas acerca da gestão dos agrotóxicos no Brasil. In: ARAGÃO, Alexandra; LEITE, José Rubens Morato; FERREIRA, Jovino dos Santos; FERREIRA, Maria Leonor Paes Cavalcanti. Agrotóxicos. A nossa saúde e o meio ambiente em questão - aspectos técnicos, jurídicos, éticos. Florianópolis: FUNJAB, 2012.

FERREIRA, Maria Leonor Paes Cavalcanti. A regulação do uso dos agrotóxicos no Brasil: uma proposta para um direito de sustentabilidade. Tese de Doutorado apresentada ao curso de PósGraduação em Direito da Universidade Federal de Santa Catarina. Florianópolis, 2013.

FUNDAÇÃO OSWALDO CRUZ/CENTRO DE INFORMAÇÃO CIENTÍFICA E TECNOLÓGICA/SISTEMA NACIONAL DE INFORMAÇÕES TÓXICO-FARMACOLÓGICAS. Estatística Anual de Casos de Intoxicação e Envenenamento. Brasil, 2011. Acesso em: 10/out./ 2013. Disponível em: http://www.fiocruz.br/sinitox.

GONÇALVES, André L. Sistemas Agroflorestais no litoral Norte do Rio Grande do Sul: produção de alimentos e conservação da Mata Atlântica. In: PORRO, Roberto; MICCOLIS, Andrew (org.). Políticas Públicas para Desenvolvimento Agroflorestal no Brasil. Belém: ICRAF, 2011. 
Disponível em: < http://www.fao.org/forestry/36079-020ee9893d541ea1 76f0df22301c7ef99.pdf>. Acesso em 15 de dezembro de 2013.

GRÍGOLO, Sernei César. Referências em Agroecologia: um olhar sobre a renda e os caminhos trilhados pela Agricultura Familiar do Sudoeste do Paraná. In: ALVES, Adilson Francelino; CARRIJO, Beatriz Rodrigues; CANDIOTTO, Luciano Zanetti Pessôa (org.). Desenvolvimento territorial e agroecologia. São Paulo: Expressão Popular, 2008.

HESPANHOL, Rosângela Ap. de Medeiros. Agroecologia: limites e perspectivas. In: ALVES, Adilson Francelino; CARRIJO, Beatriz Rodrigues; CANDIOTTO, Luciano Zanetti Pessôa (org.). Desenvolvimento territorial e agroecologia. São Paulo: Expressão Popular, 2008.

INSTITUTO BRASILEIRO DO MEIO AMBIENTE E DOS RECURSOS NATURAIS RENOVÁVEIS. Produtos agrotóxicos e afins comercializados em 2009 no Brasil: uma abordagem ambiental. Brasília: IBAMA, 2010.

LAGO, Paulo Fernando. A consciência ecológica. A luta pelo futuro. Florianópolis: UFSC, 1991.

LEFF, Enrique. Discursos Sustentáveis. São Paulo: Cortez, 2010.

LUFCHITZ, G. H. M.; BAROTTO, A. M.; ZANNIN, M. Intoxicação por agrotóxicos registradas no centro de informações toxicológicas de Santa Catarina (CIT/SC). In: ARAGÃO, Alexandra; LEITE, José Rubens Morato; FERREIRA, Jovino dos Santos; FERREIRA, Maria Leonor Paes Cavalcanti. Agrotóxicos. A nossa saúde e o meio ambiente em questão aspectos técnicos, jurídicos, éticos. Florianópolis: FUNJAB, 2012.

LUTZENBERGER, José A. Manual de Ecologia. Do Jardim ao Poder. Porto Alegre: L \& PM, 2012.

MARTINS, Mariane Cardoso. A agricultura orgânica e o desenvolvimento territorial sustentável: estudo de caso da produção agroecológica na região de Torres, RS. Trabalho de Conclusão de Curso Engenharia Ambiental da Universidade do Extremo Sul Catarinense (UNESC). Criciúma, 2012. 
MINISTÉRIO DA AGRICULTURA, PECUÁRIA E ABASTECIMENTO. Agronegócio Brasileiro em números. 2010. Disponível em: < http:// www.agricultura.gov.br/arq_editor/file/Sala\%20de\%20Imprensa/ Publica\%C3\%A7\%C3\%B5es/graficos_portugues_corrigido2.pdf>. Acesso em 20 de novembro de 2013.

MOREIRA, Rodrigo Machado; CARMO, Maristela Simões. Agroecologia na construção do desenvolvimento rural sustentável. Agricultura em São Paulo, v. 51, no.02, p. 37-56, jul./dez. 2004. Disponível em: < http:// www.iea.sp.gov.br/out/publicacoes/pdf/asp-2-04-4.pdf>. Acesso em: 01 de dezembro de 2013.

MULLER, J.M.; LOVATO, P.E; MUSSOI, E.M. Do tradicional ao agroecológico: as veredas da transição (o caso dos agricultores familiares de Santa Rosa da Lima/SC). Eisforia (UFSC), Florianópolis, v.1, n.1, p. 98-121, 2003.

NODARI, Rubens Onofre. Risco à saúde dos seres vivos advindos dos agrotóxicos - ênfase nos herbicidas. In: ARAGÃO, Alexandra; LEITE, José Rubens Morato; FERREIRA, Jovino dos Santos; FERREIRA, Maria Leonor Paes Cavalcanti. Agrotóxicos. A nossa saúde e o meio ambiente em questão - aspectos técnicos, jurídicos, éticos. Florianópolis: FUNJAB, 2012.

NUSDEO, Ana Maria de Oliveira. Pagamento por Serviços Ambientais. Sustentabilidade e Disciplina Jurídica. São Paulo: Atlas, 2012.

ORTIZ, Ramon Arigoni. Valoração econômica ambiental. In: MAY, Peter H.; LUSTOSA, Maria Cecília; VINHA, Valéria da. Economia do Meio Ambiente. Teoria e Prática. Rio de Janeiro: Elsevier, 2003.

\section{PERALTA, Carlos E. O Pagamento por Serviços Ambientais como} Instrumento para orientar a sustentabilidade ambiental. A Experiência da Costa Rica.. São Paulo: IDPV.

RECH, Adir Ubaldo. Fundamentos jurídicos da recuperação das matas ciliares e dos recursos hídricos por pagamento por serviços ambientais. In: RECH, Adir Ubaldo; ALTAMANN, Alexandre. Pagamento por Serviços 
Ambientais. Imperativos jurídicos e ecológicos para a preservação e a restauração das matas ciliares. Caxias do Sul: EDUCS, 2009.

SAQUET, Adriano Arriel. Reflexões sobre a agroecologia no Brasil. In: ALVES, Adilson Francelino; CARRIJO, Beatriz Rodrigues; CANDIOTTO, Luciano Zanetti Pessôa (org.). Desenvolvimento territorial e agroecologia. São Paulo: Expressão Popular, 2008.

SEEHUSEN, Susan Edda; PREM, Ingrid. Por que Pagamentos Por Serviços Ambientais? In: GUEDES, Fátima Becker; SEEHUSEN, Susan Edda (org.). Pagamento por Serviços Ambientais na Mata Atlântica. Lições aprendidas e desafios. Brasília: Ministério do Meio Ambiente, 2011.

SHIVA, Vandana. Monoculturas da Mente. São Paulo: Gaia, 2003.

Artigo recebido em: 14/10/2014 Aprovado para publicação em: 31/10/2014

Como citar: JODAS, Natália. PORTANOVA, Rogerio Silva. Pagamento por serviços ambientais (PSA) e Agroecologia: uma abordagem crítica à agricultura moderna. Revista do Direito Público. Londrina, v.9, n.3, p.129152, set./dez.2014. DOI: 10.5433/1980-511X.2014v9n3p129. 